\title{
Development and testing of a large, transportable rainfall simulator for plot-scale runoff and parameter estimation
}

\author{
T. G. Wilson ${ }^{1}$, C. Cortis ${ }^{2}$, N. Montaldo ${ }^{2}$, and J. D. Albertson ${ }^{1}$ \\ ${ }^{1}$ Department of Civil and Environmental Engineering, Pratt School of Engineering, Duke University, \\ Durham, NC, 27708, USA \\ ${ }^{2}$ Dipartimento di Ingegneria Civile, Ambientale e Architettura, Università di Cagliari, Cagliari, Italy \\ Correspondence to: T. G. Wilson (tiffany.g.wilson@duke.edu)
}

Received: 1 April 2014 - Published in Hydrol. Earth Syst. Sci. Discuss.: 17 April 2014

Revised: - - Accepted: 13 August 2014 - Published: 22 October 2014

\begin{abstract}
There is increased interest in the interplay between vegetation conditions and overland flow generation. The literature is unclear on this relationship, and there is little quantitative guidance for modeling efforts. Therefore, experimental efforts are needed, and these call for a lightweight transportable plot-scale $\left(>10 \mathrm{~m}^{2}\right)$ rainfall simulator that can be deployed quickly and quickly redeployed over various vegetation cover conditions. Accordingly, a variable-intensity rainfall simulator and collection system was designed and tested in the laboratory and in the field. The system was tested with three configurations of common pressure washing nozzles producing rainfall intensities of 62,43 , and $32 \mathrm{~mm} \mathrm{~h}^{-1}$ with uniformity coefficients of 76,65 , and $62 \%$, respectively, over a plot of $15.12 \mathrm{~m}^{2}$. Field tests were carried out on a grassy field with silt-loam soil in Orroli, Sardinia, in July and August 2010, and rainfall, soil moisture, and runoff data were collected. The two-term Philip infiltration model was used to find optimal values for the saturated hydraulic conductivity of the soil surface and bulk soil, soil water retention curve slope, and air entry suction head. Optimized hydraulic conductivity values were similar to both the measured final infiltration rate and literature values for saturated hydraulic conductivity. This inexpensive (less than USD 1000) rainfall simulator can therefore be used to identify field parameters needed for hydrologic modeling.
\end{abstract}

\section{Introduction}

Rainfall simulators have been used extensively to gather runoff, infiltration, and erosion data in both laboratory and field experiments. The results of these experiments are typically used for the purposes of understanding processes such as runoff and infiltration mechanisms, water routing, and sediment generation and transport at scales ranging from point to hillslope, with emphasis on how surface characteristics such as slope, aspect, soil properties, fire, vegetation, and microtopography affect these processes (e.g., Dunne et al., 1991; Bhardwaj and Singh, 1992; Foster et al., 2000; Stone et al., 2008; Fernandez-Galvez et al., 2008).

More recently, research has started to focus on the effects that changes in surface properties such as land cover or land use can have on the hydrologic cycle (e.g., GarcíaRuiz et al., 2005; Morán-Tejeda et al., 2010; Lana-Renault et al., 2011; Romero et al., 2011; Genxu et al., 2012; Maetens et al., 2012); these studies often assess how runoff and erosion at the plot and hillslope scales change as vegetation recovers from fire, agriculture, or other disturbances. Therefore, an emerging research need is the further understanding of the interplay between vegetation, additional surface properties, and runoff generation on scales from hillslope to watershed. To begin to answer this question, there is a need for broad experiments that evaluate characteristic land surfaces throughout a watershed and during the course of the year. Specifically, there is currently a lack of studies that estimate soil hydraulic properties at multiple locations in a watershed and at multiple points in time. Indeed, such measurements are needed to improve the runoff response accuracy of watershed hydrologic models. In practice, this requires a large rainfall simulator that is capable of producing high rainfall intensities and can easily be transported between field sites for multiple measurements in space and time. 
There are several different types of rainfall simulators, each with its own application, benefits, and shortcomings. The literature on rainfall simulators is extensive; for a more complete review see Battany and Grismer (2000). The standard small- or laboratory-scale $\left(1 \mathrm{~m}^{2}\right.$ or smaller) rainfall simulator is a drip tank (Cerdà et al., 1997; Foster et al., 2000; Fernandez-Galvez et al., 2008, and many others). These devices are tanks with a uniform arrangement of holes. They can produce a wide range of rainfall intensities and typically provide spatially and temporally uniform coverage. The $0.5 \mathrm{~m}^{2}$ simulator of Foster et al. (2000) produced intensities ranging from 7.74 to $28.57 \mathrm{~mm} \mathrm{~h}^{-1}$ with temporal coefficients of variation for intensity ranging from 5.04 to $11.55 \%$, and the $0.24 \mathrm{~m}^{2}$ rainfall simulator of Cerdà et al. (1997) produced $55 \mathrm{~mm} \mathrm{~h}^{-1}$ with a spatial uniformity coefficient of $93 \%$. Larger intensities are also possible; for example Fernandez-Galvez et al. (2008) used a simulator with a range of $0-120 \mathrm{~mm} \mathrm{~h}^{-1}$ with an intentionally heterogeneous distribution. The drop size and rainfall intensity in drip tank rainfall simulators are controlled by the diameter of the holes and the pressure in the tank. Another type of smallplot rainfall simulator can use nozzles with a rotating disk that directs water to the plot (originally Grierson and Oades, 1977). These devices also attain uniformity coefficients of at least $75 \%$ for a full range of intensities. In general, smallplot rainfall simulators are easily portable due to their small size. However, their limited size (approx. $1 \mathrm{~m}^{2}$ ) makes them not well suited to capturing plot-scale heterogeneity in surface properties.

For field plots (up to approximately $10 \mathrm{~m}$ per side), two standard choices for rainfall simulators are sweeping sprinklers and rows or arrays of nozzles. One of the early simulators of this type, developed by Moore et al. (1983), used oscillating nozzles to obtain intensities of $3.5-185 \mathrm{~mm} \mathrm{~h}^{-1}$ with uniformity coefficients between 80.2 and $83.7 \%$ over a $4.6 \mathrm{~m} \times 6.1 \mathrm{~m}$ plot. Similarly, the "EMIRE" (Etude et Modélisation de l'Infiltration, du Ruissellement et de l'Erosion) rainfall simulator of Esteves et al. (2000) has a base unit that irrigates a $5 \mathrm{~m} \times 5 \mathrm{~m}$ area with mean intensities from 60 to $76 \mathrm{~mm} \mathrm{~h}^{-1}$ and a mean uniformity coefficient of $80.2 \%$. Fister et al. (2012) developed a rainfall simulator for a $2.2 \mathrm{~m}^{2}$ plot that achieves $85-96 \mathrm{~mm} \mathrm{~h}^{-1}$ with a mean uniformity coefficient of $60 \%$; the emphasis was placed on reproducibility rather than uniformity in this case. One of the main advantages of these types of devices is that they can achieve higher drop velocities than drip tanks due to the water pressure in the nozzles. These devices also tend to be expandable to larger areas by reproducing the base unit. A typical disadvantage of sweeping or oscillating sprinkler rainfall simulators is that the design can include intricate parts and may need to be run by computer, adding to the system expense and complexity. Also, the spray may be intermittent instead of constant as the nozzles sweep back and forth across or rotate around a plot. A typical disadvantage of rows or arrays of spray nozzles is that they tend to have lower uniformity coefficients due to stationary nozzle patterns. The design of Esteves et al. (2000) is close to meeting our needs due to its simplicity and expandability, but the stand pipes are secured with guy wires, making the unit not freestanding and potentially difficult to move or install in desired locations.

Finally, for larger plots on the hillslope scale, the standard design is a rotating boom rainfall simulator, first developed by Swanson (1965). A single unit of this simulator irrigates two parallel plots of $4.3 \mathrm{~m} \times 10.7 \mathrm{~m}$ at up to $120 \mathrm{~mm} \mathrm{~h}^{-1}$ intensity, with two units used to cover plots up to about $23 \mathrm{~m}$ long. In addition to covering large areas, these systems can be mounted on a trailer, simplifying transportation between sites. However, trailer-mounted systems cannot be used on steep hillslopes or in other areas that vehicles cannot reach, such as forests, which does not make them well suited for use in the wide range of soil and vegetation combinations needed for the present research. Additionally, these systems are usually more complicated than drip tanks or stationary nozzle systems, and due to the circular spray pattern, these systems are less efficient for covering square or rectangular plots.

Overall, lacking standard designs for rainfall simulators, individual researchers develop devices that suit their particular needs. In this case, the need is for an inexpensive, mechanically simple rainfall simulator system that achieves reasonable uniformity and can be used to accurately estimate soil characteristics such as the saturated hydraulic conductivity in a wide variety of vegetated locations. Such a device should be easily constructed in areas where access to specialized components is limited, easily repaired should any components of the system break, and easily transported from one field plot to the next. An additional requirement is that the plot is significantly larger than a single vegetation patch in order to capture the net runoff response that results from the re-infiltration of surface runoff.

To this end, this paper describes the design and testing of a rainfall simulator using primarily components that can be found in any hardware store. The system irrigates an area of approximately $15 \mathrm{~m}^{2}$ with a range of rainfall intensity rates. In field tests of the system in Sardinia, Italy, data collected included soil moisture throughout the plot and runoff collected using a tipping bucket flow gauge.

The intended use of this system is to estimate soil hydraulic properties, primarily the saturated hydraulic conductivity $\left(K_{\mathrm{S}}\right)$. There is a long history of using field data and numerical inversion to estimate soil parameters (e.g., Kool et al., 1985; Russo et al., 1991; Simunek and van Genuchten, 1996; Lassabatere et al., 2006; Ramos et al., 2006; Xu et al., 2012; Rienzner and Gandolfi, 2014). However, these experiments typically use point measurements from instruments such as single ring permeameters or tension disk infiltrometers and therefore do not capture the effective response at the plot scale. Some studies have focused on vertical variability of $K_{\mathrm{S}}$ (Olyphant, 2003; Segal et al., 2008), but few have worked at the plot or hillslope scale. Ram et al. (2012) performed experiments on $4 \mathrm{~m}$ wide border strips and used 
nonlinear optimization to estimate the van Genuchten parameters $\alpha$ and $n$, but fixed $K_{\mathrm{s}}$ based on Guelph permeameter measurements. Also, Verbist et al. (2009) carried out rainfall simulation experiments on $6 \mathrm{~m} \times 2 \mathrm{~m}$ plots and determined that the values of $K_{\mathrm{S}}$ resulting from fitting the twoterm Philip infiltration model to measured data were comparable to the values obtained using full nonlinear optimization. Following this approach, we seek to use this new rainfall simulator and simplified parameter estimation methods to calculate physically reasonable values of the saturated hydraulic conductivity of the soil surface and soil below the surface. Overall, this device will improve the ability of researchers to make more soil hydraulic property measurements over space and time that accurately assess plot-scale runoff response.

\section{Rainfall simulator system design}

Generally, there are 10 important criteria for ideal rainfall simulators (Moore et al., 1983):

1. drop size distribution similar to that of natural rainfall,

2. drop velocity similar to that of natural rainfall,

3. uniform intensity and random drop size distribution over the plot,

4. continuous application over the plot,

5. nearly vertical impact angle,

6. reproducible storm durations and intensities,

7. ability to perform in conditions such as high temperatures and wind,

8. sufficient areal coverage to meet needs of experiment,

9. plot-to-plot and site-to-site portability,

10. low cost.

Typically, there is some compromise among the criteria as it is difficult to meet all of them. In addition to the primary objective of ease of portability, the choice was made to emphasize low cost, areal coverage, and reproducibility, with the added objective of being able to meet these criteria at at least two different rainfall intensities.

\subsection{Simulator components}

The rainfall simulator consists of several parts: nozzle lines, nozzle supports, structural frame, and water delivery system. The four independently operated nozzle lines have either 11 or 12 nozzle assemblies (46 total) connected with $1.5 \mathrm{~cm}$ inner-diameter PVC pipe and compression fittings. Each nozzle assembly, as shown in Fig. 1a, consists of a $0.5 \mathrm{~mm}$ opening pressure washing nozzle, threaded hex connector, and threaded hose barb. The barbed ends of the hose
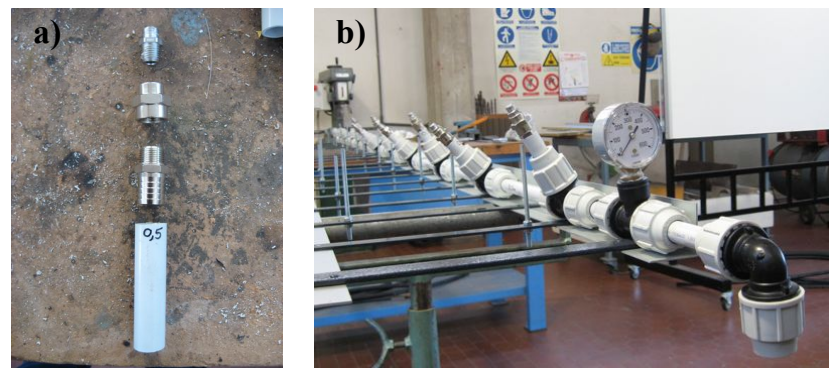

Figure 1. Nozzle line setup. (a) Nozzle assembly. The threaded pressure washing nozzle was connected to a short length of PVC pipe using two connectors. (b) Alternating angles of nozzles and pressure gauge used to regulate flow.

barbs were wrapped in teflon tape and gently hammered into a short length of PVC pipe, which was then attached to the compression tees on the main line as shown in Fig. 1b. The centers of the nozzles are $33.3 \mathrm{~cm}$ apart; the lengths of pipe between the nozzles were cut to attain this length and will vary based on the pipe fittings used in other applications. Each line is a total of $4.2 \mathrm{~m}$ long with a plugged length of pipe at one end and a $0-600$ mbar pressure gauge and elbow at the other end that connects to the water delivery system. The nozzle lines are configured as shown in Fig. 2a, with two sets of nozzles that face each other at a distance of $2.3 \mathrm{~m}$ apart.

The nozzle assemblies are supported by L-shaped pieces of metal mounted to stiff metal rods as shown in Fig. 1b. The nozzles point upwards at alternating angles of 48 and $54^{\circ}$ from horizontal; the drops then fall from a height of approximately $3 \mathrm{~m}$. Shorter lengths of the stiff rod support $15 \mathrm{~cm}$ bolts that are used to set and maintain the angle. Plastic zip ties hold the nozzles in place on top of the bolts during the experiments. Other than the spacing and angles of the nozzles, other aspects of the support system may be adapted to suit the needs and available materials of other researchers.

The structural frame, shown in schematic in Fig. 3, consists of six $2 \mathrm{~m}$ vertical beams, three $4 \mathrm{~m}$ horizontal beams to which the nozzles are mounted, and two $4 \mathrm{~m}$ horizontal beams to complete the frame, for overall measurements of $4 \mathrm{~m} \times 4 \mathrm{~m} \times 2 \mathrm{~m}$. The present frame uses $6 \mathrm{~cm}$ metal tubing with clamp connectors since they were readily available, but other materials may be used; Schedule 40 PVC is a good inexpensive alternative. Additionally, a plastic mesh attached to the final two horizontal beams helps randomize the spray pattern (Foster et al., 2000). The mesh is a heavy-gauge $4 \mathrm{~mm}$ grid mesh that is doubled along the edges to prevent ripping and attached to the frame using plastic mesh clips and zip ties to prevent sagging.

The water delivery system conveys water from the $2 \mathrm{~m}^{3}$ tank to the nozzle lines. A submersible pump with a filter, powered by a gasoline generator, pumps water out of the tank via flexible hose. Three tees are used to split the single line 


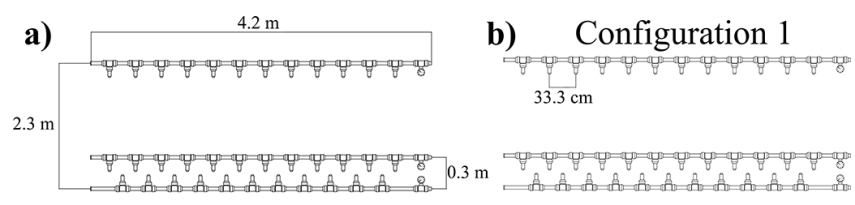

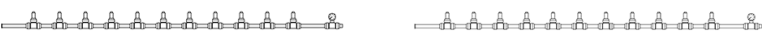

c)

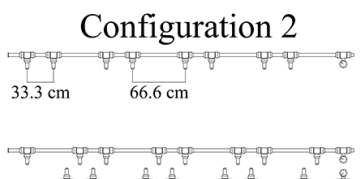

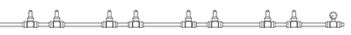

d)
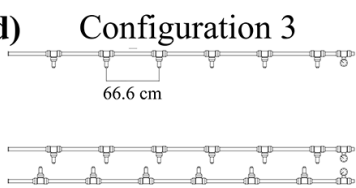

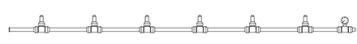

Figure 2. Nozzle configurations for three intensities with nozzle spacing, resulting intensity, and experimental coefficient of uniformity of water application. (a) Spacing between nozzle lines. (b) 46 nozzles, $61.6 \mathrm{~mm} \mathrm{~h}^{-1}, \mathrm{CU}=75.64 \%$. (c) 31 nozzles, $43.3 \mathrm{~mm} \mathrm{~h}^{-1}, \mathrm{CU}=65.16 \%$. (d) 24 nozzles, $31.8 \mathrm{~mm} \mathrm{~h}^{-1}, \mathrm{CU}=$ $62.1 \%$.

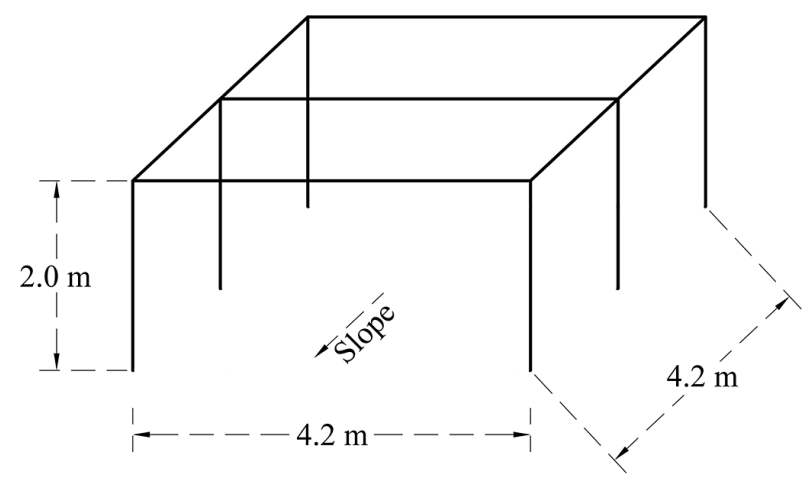

Figure 3. Schematic of the rainfall simulator frame.

into four, and each of these four lines contains a butterfly valve near the pressure gauges so the pressure can be adjusted if necessary.

The overall cost of the rainfall simulator in 2010 was less than USD 1000. This cost includes the simulator components above and the instrumentation discussed below. The dimensions and operating parameters should be matched to what is discussed here, but other components may be changed to suit the needs of other researchers.

\subsection{Instrumentation and data collection}

An in-line volumetric flow meter on the tubing between the pump and the nozzle lines measured the total amount of water delivered to the system. The reading on this flow meter was recorded at the beginning and end of each experiment. Time domain reflectometry probes (Campbell Scientific CS616) were used to measure soil moisture. Due to the presence of large rocks in the soil below $20 \mathrm{~cm}$ and the desire to take measurements in a regular grid and over a uniform depth, the probes were inserted at approximately a $30^{\circ}$ angle from horizontal to measure the top $15 \mathrm{~cm}$ of the soil. This depth corresponds to the root zone for grassy vegetation. A data logger recorded readings from the probes at $1 \mathrm{~s}$ intervals. To measure the amount of water delivered to the plot, two $10 \mathrm{~cm}$ simple rain gauges were placed inside the irrigated area.

Runoff from the plot was collected using a tipping bucket flow gauge (Fig. 4) based on the design of Chow (1976). The metal box is open on the sides and supports two plexiglas buckets that hold approximately $2 \mathrm{~L}$ each. The recording mechanism is the magnetic switch component taken from a tipping bucket rain gauge. Water flows into the bucket from a hose attached to the back of the structure (see Fig. 4b), and the data logger records the time of the pulse created by each tip. At the current field site, the amount of sediment was considered to be negligible compared to the mass of water. Additionally, no sediment appeared to collect in the buckets. In applications with higher erosion rates, a screen could be placed above the flow gauge to filter sediment from the runoff. Finally, it is worth noting that the tipping bucket was developed to take advantage of materials already on hand at the time of construction. Any of a number of other methods of measuring flow may be used to suit the needs of other investigators.

Since the tipping of the bucket is not instantaneous, the amount of water in the bucket can vary with the flow rate. Specifically, while the mass of water needed to make the bucket tip is constant, water continues to collect in the bucket as it tips. Therefore, a higher flow rate can result in a higher volume of water in each bucket. To calibrate the flow gauge for this effect, water with a known flow rate $q$ was directed into the flow gauge and the instrument was video-recorded for the amount of time needed for several tips to occur. The volume in each of the tip of the bucket was inferred from the flow rate and the amount of time the water stream spent in the bucket, $V=q\left(t_{\mathrm{exit}}-t_{\mathrm{enter}}\right) \cdot t_{\mathrm{enter}}$ and $t_{\mathrm{exit}}$ were gathered from the time stamps on the corresponding frames of the video. This process was repeated several times at different known flow rates. Figure 5 shows the data points and regression of the bucket volume as a function of the tipping frequency as tested in the lab, namely

$V=0.0144 f+2.15$,

where $f$ is the frequency in tips per minute and $V$ is the bucket volume in liters. The volume is nearly constant, only ranging between 2.1 and $2.3 \mathrm{~L}$ per tip, but the data do show a weak dependence on tipping rate. For each pulse recorded during the experiments, the corresponding number of tips per minute was calculated as $f=1 /\left(t_{i}-t_{i-1}\right)$, where $t$ is measured in minutes; then Eq. (1) was used to calculate the expected volume. 

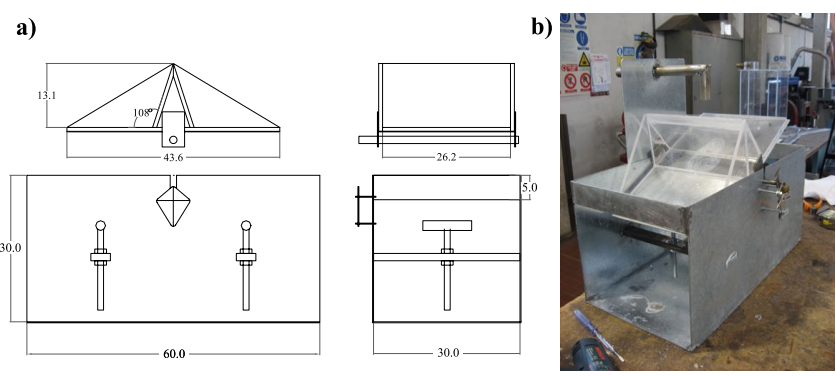

Figure 4. Tipping bucket flow gauge. (a) Dimensions of the flow gauge. All dimensions in centimeters. (b) Completed flow gauge constructed from sheet metal and plexiglas.

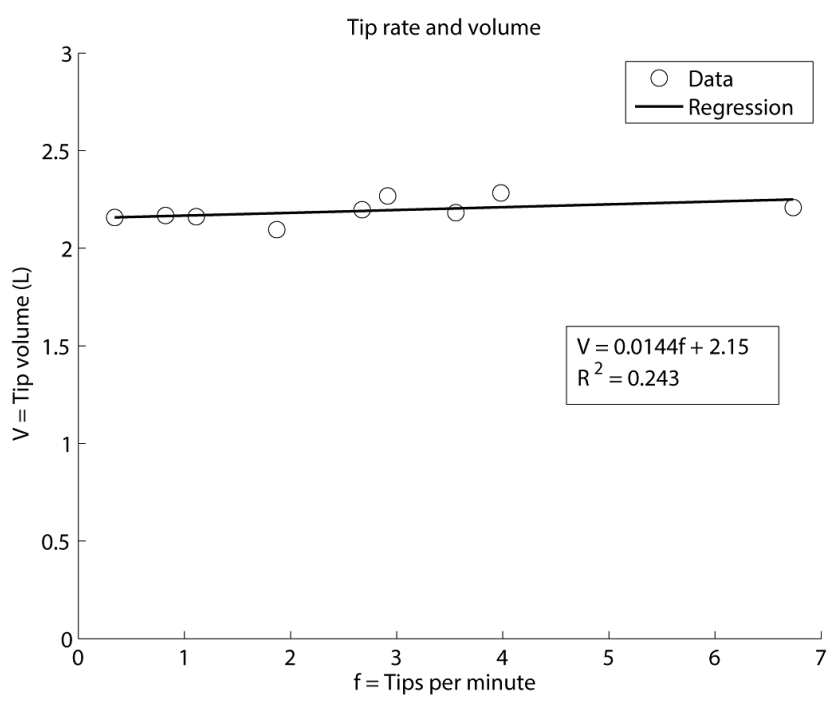

Figure 5. Data and regression for bucket volume as a function of tipping frequency.

\subsection{Simulator logistics}

The components of the rainfall simulator can fit on a small truck with a flat bed approximately $3-4 \mathrm{~m}$ long. Once on site, it takes four people approximately $90 \mathrm{~min}$ to set up the rainfall simulator. Ideally, the water tank will be located close to the plot to reduce the pressure required of the submersible pump, so the tank should be able to be filled on site. If the simulator is to be moved to a nearby plot, it can be picked up by four people and walked to the new location instead of disassembled and reassembled, leaving only the soil moisture sensors, plot border, and collection system to be re-installed.

Operation of the rainfall simulator can be accomplished with a staff of three to four people. Once the simulator and other components are installed, the generator is started and the pump is turned on. The simulator is run for a short time to prime the system, adjust the butterfly valves so each pressure gauge reads $100 \mathrm{mbar}\left(8 \times 10^{3} \mathrm{~Pa}\right)$, and verify that the data logger is working. Then, the starting value of the in-line flow meter and start time are recorded as the system pump is turned back on. During operation, it is useful to have one person monitoring the pressure in the nozzle lines, another monitoring the tipping bucket, and a third person observing the plot to record when and where ponding occurs and to make sure water is draining properly. To turn off the system after the desired experiment time, the pump is turned off and the butterfly valves are closed. The data logger is allowed to continue recording until runoff stops.

\section{Rainfall simulator testing}

Before using the rainfall simulator in the field, laboratory tests were performed to determine the uniformity of the depth of water in the plot with several configurations. Figure 2 shows three potential configurations for this particular system. If a nozzle was not used in a given configuration, it was removed and replaced with a short plugged length of PVC pipe. The first configuration (Fig. 2b) has 46 nozzles, with $33.3 \mathrm{~cm}$ between the center of each nozzle. In the second configuration, which has 31 nozzles, every third nozzle is removed, resulting in nozzle spacings of 33.3 and $66.6 \mathrm{~cm}$. The third configuration has 24 nozzles, with $66.6 \mathrm{~cm}$ between all nozzles.

For each configuration, the simulator was run for $30 \mathrm{~min}$ with water collected in 63 containers arrayed beneath the sprinklers. The $10 \mathrm{~cm}$ diameter collection containers were placed in an array with nine containers in the direction of the ground slope and seven containers in the direction perpendicular to the ground slope, both with $50 \mathrm{~cm}$ spacing. The uniformity of the applied water was calculated using the Christiansen coefficient of uniformity (CU; Christiansen, 1942):

$\mathrm{CU}=100 \cdot\left(1-\frac{\sum|x-\bar{x}|}{n \bar{x}}\right)$,

where $\bar{x}$ is the average of all of the measurements, $\sum|x-\bar{x}|$ is the sum of the individual deviations from the mean, and $n$ is the number of measurements taken. Figure 6 shows the rainfall intensity for the three nozzle configurations, and a summary of the configuration performance is shown in Table 1 . The three configurations - with 46,31 , and $24 \mathrm{noz}-$ zles - had average rainfall intensities of $61.6,43.3$, and $31.8 \mathrm{~mm} \mathrm{~h}^{-1}$, respectively. The standard deviations of the three configurations of $18.2,18.9$, and $14.9 \mathrm{~mm} \mathrm{~h}^{-1}$ are similar to those of the basic unit of the EMIRE rainfall simulator, which covers a similar area using stationary nozzles (Esteves et al., 2000). Since each configuration has an operating pressure of $8 \times 10^{3} \mathrm{~Pa}$, the average intensity decreases with a decreasing number of nozzles. However, the coefficient of uniformity also decreases with fewer nozzles due to less spatial coverage of the plot. Ideally, one seeks a CU near $80 \%$ (e.g., Neff, 1979); however, in the present application there is a trade-off between uniformity and other objectives, such as size, cost, and portability. Accordingly, while the CU 
Table 1. Summary of nozzle configurations and performance.

\begin{tabular}{cccccc}
\hline Configuration & No. of nozzles & $\begin{array}{c}\text { Pressure } \\
\left(\mathrm{Pa} \times 10^{3}\right)\end{array}$ & $\begin{array}{c}\text { Mean intensity } \\
\left(\mathrm{mm} \mathrm{h}^{-1}\right)\end{array}$ & $\begin{array}{c}\text { Standard deviation } \\
\left(\mathrm{mm} \mathrm{h}^{-1}\right)\end{array}$ & $\begin{array}{c}\text { Coefficient of uniformity } \\
(\%)\end{array}$ \\
\hline 1 & 46 & 8 & 61.6 & 18.2 & 75.7 \\
2 & 31 & 8 & 43.3 & 18.9 & 65.2 \\
3 & 24 & 8 & 31.8 & 14.9 & 62.1 \\
\hline
\end{tabular}
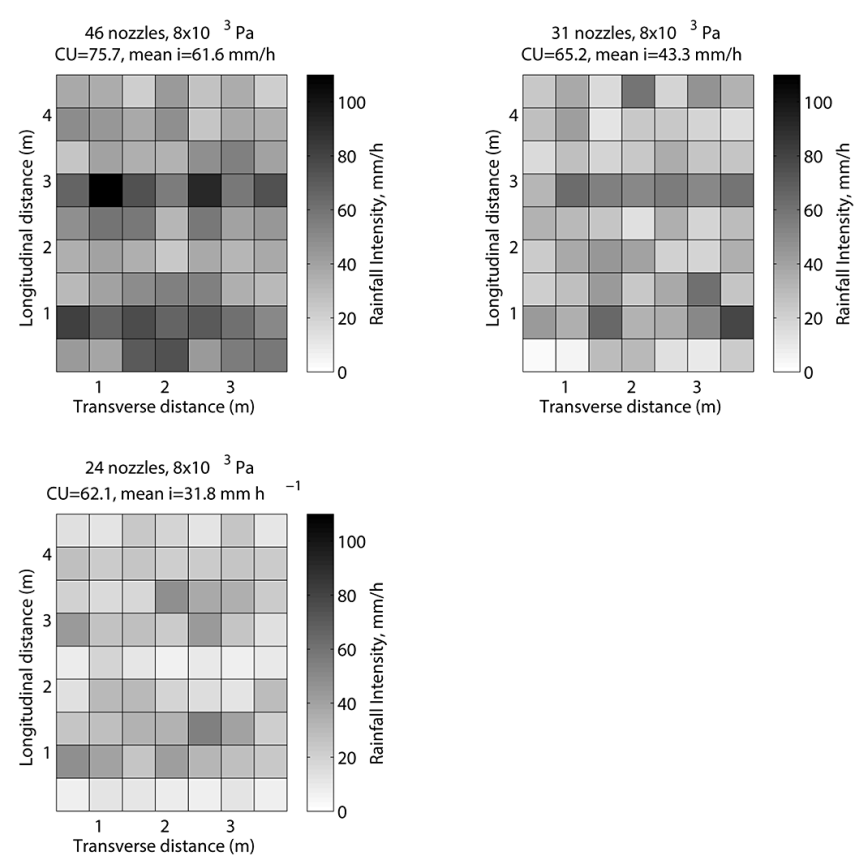

Figure 6. Distribution of rainfall intensities and coefficient of uniformity for the three nozzle configurations.

values of 75,65 , and $62 \%$ are not ideal, they are a reasonable compromise for the objective of emphasizing the applicability and reproducibility of the results over the uniformity (Fister et al., 2012). Additionally, rainfall simulators with the highest $\mathrm{CU}$ values are typically the smallest $\left(1 \mathrm{~m}^{2}\right.$ range); therefore we consider the present $\mathrm{CU}$ values to be acceptable based on the size of the plot under consideration.

Drop size distributions (DSDs) were measured with a disdrometer for several locations within the irrigation area for both configuration $1\left(61.6 \mathrm{~mm} \mathrm{~h}^{-1}\right)$ and configuration 3 $\left(31.8 \mathrm{~mm} \mathrm{~h}^{-1}\right)$. In each case, the DSDs for the number of drops in $300 \mathrm{~s}$ ranged from 0.25 to $3.3 \mathrm{~mm}$ drop diameter. The maximum peak frequency occurred at $1 \mathrm{~mm}$, with additional peaks at 2 and $2.6 \mathrm{~mm}$. These results are similar to those documented by Sauvageout and Lacaux (1995). Additionally, drop velocities from the rainfall simulator height were determined to reach terminal velocity for diameters less than $1.5 \mathrm{~mm}$, which covers the peak diameter frequency. The full details of the disdrometer and velocity analyses are shown in Corona (2013).

\section{Field experiments}

\subsection{Field site}

The experiments were carried out at an existing field site in Orroli, Italy, on the island of Sardinia $\left(39^{\circ} 41^{\prime} 12.57^{\prime \prime} \mathrm{N}\right.$, $9^{\circ} 16^{\prime} 30.34^{\prime \prime} \mathrm{E}$ ) in July and August 2010. The site was accessible by a path leading downhill from the road for approximately $200 \mathrm{~m}$. The simulator components were carried from the road to the site and assembled around the chosen plot. The water tank was carried to the site while empty and then filled from a water truck located on the road.

In the chosen field plot, tall grasses covered approximately $95 \%$ of the ground surface, and the land has a gentle slope of approximately $4.6^{\circ}$. The soil is a silt loam with bulk density of $1.38 \mathrm{~g} \mathrm{~cm}^{-3}$ (Montaldo et al., 2008). The choice of a vegetated plot is intentional, as future work with this rainfall simulator will be to assess the effect of vegetation on the estimated soil parameters.

Around the frame of the rainfall simulator, thin sheet metal was inserted approximately $10 \mathrm{~cm}$ into the ground to help prevent lateral flow of water across the plot boundaries. To collect the surface runoff, a shallow trench was dug at the bottom edge of the plot, and a plastic ledge was inserted into the ground just below the surface to direct the water onto plastic sheeting. From here, the water flowed by gravity into a tube that was connected to the tipping bucket flow gauge. As shown in Fig. 7, the soil moisture probes were placed at $1 \mathrm{~m}$ intervals in the irrigated section of the plot. Additionally, to verify rainfall intensity, two rain gauges were placed inside the plot. A slight rill already existed in the plot due to an animal footpath, and as a result the outlet of the plot was approximately at the location of soil moisture probe 14 .

\subsection{Experiments}

Three experiments were conducted over the course of several days. Each experiment had a different combination of initial soil moisture $\left(\theta_{0}\right)$, experiment duration $(T, \mathrm{~min})$, and rainfall intensity $\left(p, \mathrm{~mm} \mathrm{~h}^{-1}\right)$. For each experiment period, the rainfall was allowed to continue until the soil moisture and runoff reached a constant rate. The test conditions are described in Table 2. 


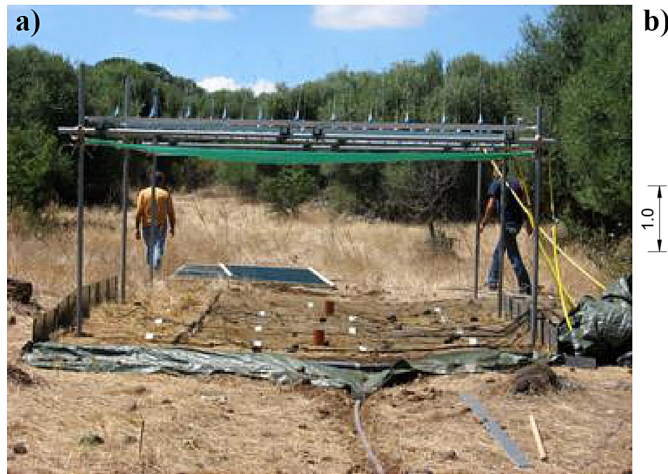

b)

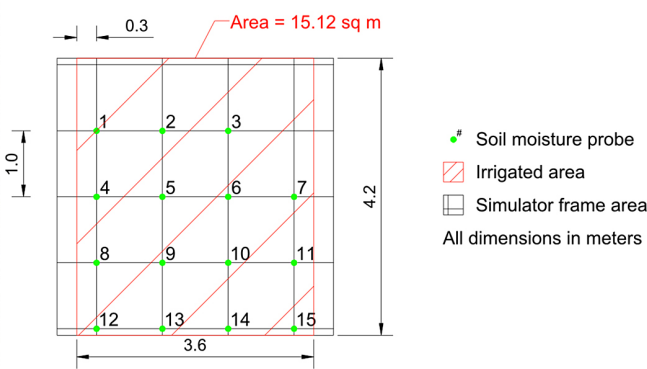

Figure 7. Field experiment setup. (a) Field setup, including soil moisture probes, border around edges, rain gauges, nozzles, distribution mesh, and collection system. (b) Details of the plot area, with soil moisture probe location and effective coverage area. The outlet of the plot is at probe 14 .

Table 2. Field test conditions.

\begin{tabular}{ccccc}
\hline Exp \# & Date & $\begin{array}{c}\theta_{0} \\
(-)\end{array}$ & $\begin{array}{c}p \\
\left(\mathrm{~mm} \mathrm{~h}^{-1}\right)\end{array}$ & $\begin{array}{c}T \\
(\mathrm{~min})\end{array}$ \\
\hline 1 & 29 Jul & 0.50 & 61.6 & 37 \\
2 & 3 Aug & 0.32 & 61.6 & 90 \\
3 & 5 Aug & 0.38 & 31.8 & 169 \\
\hline
\end{tabular}

\section{Method of soil parameter estimation}

The intended use of this rainfall simulator is to glean surface properties from rainfall experiments. Alberts et al. (1995) demonstrated a sufficient fit of an infiltration model to observed data can be found by running the model with a range of values for the saturated hydraulic conductivity and selecting the value that minimizes model error with respect to the observed infiltration. This method can be applied here to obtain $K_{\mathrm{s} \text {,bulk }}$ and $K_{\mathrm{s} \text {, surf }}$ from the experiment data in a similar manner as Verbist et al. (2009). Here, we define $K_{\mathrm{s}, \text { surf }}$ and $K_{\mathrm{s} \text {,bulk }}$ to be the saturated hydraulic conductivities of the surface layer and remainder of the soil profile, respectively. We use these two values rather than one $K_{\mathrm{S}}$ value to separate the behavior of the soil surface, which determines the amount of water that infiltrates, from that of the bulk soil, which determines overall soil water content. Based on previous work for this site (Montaldo et al., 2008), the estimated saturated hydraulic conductivity for this soil is approximately $18 \mathrm{~mm} \mathrm{~h}^{-1}$, and since land use and vegetation cover have not changed at the site, the estimate is still considered accurate to an order of magnitude. Therefore, if $K_{\mathrm{s}}$ values obtained from model fitting are close to this previous estimate, then the rainfall simulator indeed performs as intended.
A common model for infiltration is the two-parameter Philip equation (Philip, 1957):

$i_{t}^{*}=\frac{1}{2} S_{t} t^{-1 / 2}+A_{t}$,

where $i^{*}\left[\mathrm{~L} \mathrm{~T}^{-1}\right]$ is the infiltration rate at time $t$ under ponded conditions, $S_{t}\left[\mathrm{~L} \mathrm{~T}^{-1 / 2}\right]$ is the sorptivity, and $A_{t}\left[\mathrm{~L} \mathrm{~T}^{-1}\right]$ is a parameter similar to, but not necessarily equal to, the saturated hydraulic conductivity $K_{\mathrm{s}}$. It is used in this analysis because of its simplicity and success on short timescales. In this implementation, the sorptivity expression of Sivapalan et al. (1987) is used:

$$
\begin{gathered}
S_{t}=\left[\left(2 K_{\mathrm{s}, \text { surf }}\left(\theta_{\mathrm{s}}-\theta_{t}\right)^{2}\left(-\frac{\psi_{\mathrm{ae}}}{\theta_{\mathrm{s}}-\theta_{\mathrm{h}}}\right)\right)\right. \\
\left.\left(\frac{1}{(2 b+3)+\frac{1}{2 b}-1}+\frac{\theta_{\mathrm{s}}-\theta_{\mathrm{h}}}{\theta_{\mathrm{s}}-\theta_{t}}\right)\right]^{1 / 2},
\end{gathered}
$$

where $K_{\mathrm{s} \text { surf }}$ is the saturated hydraulic conductivity of the surface layer $\left[\mathrm{L} \mathrm{T}^{-1}\right], \theta_{\mathrm{s}}$ is the saturated volumetric soil moisture (porosity), $\theta_{t}$ is the volumetric soil moisture at time $t, \theta_{\mathrm{h}}$ is the hydrostatic (minimum) volumetric soil moisture, $\psi_{\mathrm{ae}}$ is the air entry suction head [L], and $b$ is the soil water retention curve parameter (Clapp and Hornberger, 1978). Eagleson (1978) showed the application of Philip's (1960) work on the diffusion equation on short timescales as

$A=\frac{1}{2}\left(K_{\mathrm{s}}+K_{0}\right)$.

Using the Campbell (1974) definition of hydraulic conductivity for the surface layer as $K_{\text {surf }}=K_{\mathrm{s}, \operatorname{surf}}\left(\theta_{t} / \theta_{\mathrm{s}}\right)^{2 b+3}$, Eq. (5) may be written as a dynamic parameter, namely

$$
A_{t}=\frac{1}{2} K_{\mathrm{s}, \operatorname{surf}}\left(1+\left(\theta_{t} / \theta_{\mathrm{S}}\right)^{2 b+3}\right) \text {. }
$$

The unsaturated hydraulic conductivity of the bulk soil is also calculated using the definition of Campbell (1974), 
namely

$K_{t, \text { bulk }}=K_{\mathrm{s}, \text { bulk }}\left(\frac{\theta_{t}}{\theta_{\mathrm{S}}}\right)^{2 b+3}$,

where $K_{\mathrm{s}, \text { bulk }}\left[\mathrm{L} \mathrm{T}^{-1}\right]$ is the saturated hydraulic conductivity of the bulk soil rather than the soil surface.

The calculation of soil moisture comes from a onedimensional water balance on a soil layer with thickness $\Delta z$, beginning with $\Delta S=V_{\text {in }}-V_{\text {out }}$, where $S$ is the water storage in the layer, $V_{\text {in }}$ is the water entering the layer, and $V_{\text {out }}$ is the water exiting the layer. $S$ can be represented as $\theta \Delta z$, so $\Delta S=\Delta z\left(\theta_{t}-\theta_{t-\Delta t}\right) . V_{\text {in }}$ is the water infiltrating from above, so during a small time step $\Delta t, V_{\text {in }}=i \Delta t$. Neglecting evapotranspiration, $V_{\text {out }}$ is the drainage of water through the bottom of the layer. Use of Darcy's law, $v=-K \frac{\mathrm{d} h}{\mathrm{dz}}$, with a unit gradient yields $V_{\text {out }}=K \Delta t$. Therefore, the soil moisture prediction equation is

$$
\begin{aligned}
\frac{\theta_{t}-\theta_{t-\Delta t}}{\Delta t} z & =i_{t}-K_{t, \text { bulk }}, \text { or } \\
\theta_{t} & =\theta_{t-\Delta t}+\left(i_{t}-K_{t, \text { bulk }}\right) \frac{\Delta t}{z},
\end{aligned}
$$

where $z[\mathrm{~L}]$ is the soil depth being considered and $i_{t}\left[\mathrm{~L} \mathrm{~T}^{-1}\right]$ is the actual infiltration rate, defined by

$i_{t}=\min \left(i_{t}^{*}, p\right)$.

See Table 3 for the parameters used in this analysis.

Infiltration is modeled using the above equations with a time step of $\Delta t=1 \mathrm{~min}$. First, $A_{t}$ and $S_{t}$ are calculated according to Eqs. (6) and (4). Then, $i_{t}^{*}$ and $i_{t}$ are calculated using Eqs. (3) and (9). The current bulk soil hydraulic conductivity is calculated with Eq. (7), and then the bulk soil moisture $\theta_{t}$ is calculated using Eq. (8).

Since Eq. (3) is defined under ponded conditions, a correction must be made to the time used in the infiltration calculations to account for the time before ponding actually begins. Dingman (2004) accomplishes this using a condensed ponding time $\left(t_{\mathrm{cp}}\right)$, which acts to delay the start of runoff in the Philip model. Without it, modeled runoff begins significantly earlier than observed runoff. Following Dingman's approach, $t_{\mathrm{S}}$ is defined as the first time in the original calculations when $p>i_{t}^{*}$. The total potential volume that can infiltrate before $t_{\mathrm{s}}$ is

$I_{\mathrm{p}}=\sum_{t=0}^{t_{\mathrm{S}}} i_{t}^{*} \Delta t$

and since $p<i_{t}^{*}$ in this time period, the time it takes for the volume $I_{\mathrm{p}}$ to infiltrate is

$t_{\mathrm{p}}=\frac{I_{\mathrm{p}}}{p}$.
Table 3. Parameters used in Philip infiltration model.

\begin{tabular}{llll}
\hline Symbol & Value & Units & Source \\
\hline$\theta_{\mathrm{s}}$ & 0.568 & {$[-]$} & Field data \\
$\theta_{\mathrm{h}}$ & 0.08 & {$[-]$} & Montaldo et al. (2008) \\
$\psi_{\mathrm{ae}}$ & 0.79 & {$[\mathrm{~m}]$} & Clapp and Hornberger (1978) \\
$b$ & 8 & {$[-]$} & Clapp and Hornberger (1978) \\
$z$ & 0.15 & {$[\mathrm{~m}]$} & Field data \\
\hline
\end{tabular}

The condensed ponding time is

$t_{\mathrm{cp}}=t_{\mathrm{p}}-t_{\mathrm{s}}$,

which can be thought of as a correction for when runoff will actually begin compared to when it would start under ponded conditions.

Then, the above calculations for $i_{t}, K_{t \text {, bulk }}$, and $\theta_{t}$ are repeated using $\hat{t}=t-t_{\mathrm{cp}}$ in place of $t$, generating the values $i_{\hat{t}}$, $K_{\hat{t} \text {,bulk }}$, and $\theta_{\hat{t}}$, which now account for the ponding correction. Finally, the modeled runoff is calculated as

$q_{\hat{t}}=\max \left(p-i_{\hat{t}}, 0\right)$.

Equations (3), (4), and (6) show that the infiltration of water through the surface, and accordingly the runoff, depend strongly on $K_{\mathrm{s} \text {, surf }}$ but not on $K_{\mathrm{s}, \text { bulk }}$. Likewise, Eqs. (8) and (7) show that $K_{\mathrm{s} \text {, bulk }}$ affects $\theta_{t}$ but not $i_{t}$. Therefore, for a period of total duration $T$ and cumulative runoff $Q$,

$e_{Q_{T}}=\left|Q_{T, \bmod }-Q_{T, \mathrm{obs}}\right|$

and

$e_{\theta}=\left(\frac{\sum_{\hat{t}=t=0}^{T}\left(\theta_{\hat{t}, \mathrm{mod}}-\theta_{t, \mathrm{obs}}\right)^{2}}{T}\right)^{1 / 2}$

can be used as measures of error that, when minimized, indicate the optimal values of $K_{\mathrm{s} \text { surf }}$ and $K_{\mathrm{s}, \text { bulk }}$, respectively. $e_{Q_{T}}$ uses the final $Q$ value to capture the overall behavior of the plot in producing runoff, and $e_{\theta}$ uses the time series of $\theta$ to capture the evolution of soil moisture during the experiment.

To optimize $K_{\mathrm{s} \text {, surf }}$ and $K_{\mathrm{s} \text {, bulk }}$, the infiltration model was run using all combinations of the two values ranging from 1 to $30 \mathrm{~mm} \mathrm{~h}^{-1}$ at a step of $\Delta K=10^{-7} \mathrm{~m} \mathrm{~s}^{-1}=0.36 \mathrm{~mm} \mathrm{~h}^{-1}$. $e_{Q_{T}}$ and $e_{\theta}$ were calculated for each combination, and the combination with the smallest value of

$e^{*}=e_{Q_{T}}+e_{\theta}$

was selected for the optimal values of $K_{\mathrm{s}, \text { surf }}$ and $K_{\mathrm{s} \text {,bulk }}$. 


\section{Results and discussion}

\subsection{Soil moisture}

While the ultimate goal is to accurately model the infiltration and runoff at the plot scale, soil moisture values can be used in the calculation of soil saturated hydraulic conductivity. Since the soil moisture values vary throughout the plot, spatial averaging of the measured data is employed. However, examining the spatial variability within the plot allows for a better understanding of each experiment.

According to previous fieldwork at this site (Montaldo et al., 2008) and examination of the measured soil moisture at saturation, the soil has an average porosity of $\theta_{\mathrm{s}}=0.568$. However, the saturation value at each individual probe location varies. In order to ease the analysis of the soil moisture, the values were scaled using

$\hat{\theta}_{x, i}=\frac{\theta_{x, i}}{\max \left(\theta_{x}\right)}$,

where $\theta_{x, i}$ is the reading from probe $x$ at time $t_{i}, \max \left(\theta_{x}\right)$ is the maximum reading for probe $x$ during the experiment, and $\hat{\theta}_{x, i}$ is the scaled value. The initial soil moisture $\theta_{0}$ as shown in Table 2 was then represented as

$\theta_{0}=\operatorname{mean}\left(\hat{\theta}_{x, 0}\right) \cdot \theta_{\mathrm{s}}$.

The first experiment, performed on 29 July (Fig. 8a), occurred after several test runs of the rainfall simulator, so the soil was close to saturated when the experiment began with $0.82 \leq \hat{\theta}_{x, 0} \leq 0.96$ and a mean value of 0.89 . Most of the plot reached saturation between 10 and 15 min after the experiment began.

The second experiment, performed on 2 August (Fig. 8b), began with $0.41 \leq \hat{\theta}_{x, 0} \leq 0.76$ and a mean value of 0.57 . A variety of paths to saturation is present. The probes that take longer to reach saturation are all near the edges of the irrigated area, so the slower increase in soil moisture may be due to lateral flow of water from the edges of the irrigated area to areas that are within the plot but not receiving water (see Fig. 7b). For instance, probes 1 and 15, which do not reach saturation during the experiment, are on the border of the irrigated area, as is probe 12 , which takes much longer to show an increase in soil moisture than the other probes. Aside from probes 1 and 15, the remainder of the plot reached saturation by approximately minute 90 of rainfall at an intensity of $61.6 \mathrm{~mm} \mathrm{~h}^{-1}$.

Another feature of the measurements for this experiment is an abrupt change in the time rate of change of soil moisture (i.e., slope of $\hat{\theta}_{x}$ vs. $t$ ) for some portions of the plot. This is particularly evident in probes $3,12,13$, and 14 . Considering just the bottom row of the plot, this change occurs first at probe 14 , followed by probe 13 then probe 12 . This progression seems to suggest that these probe locations change from having water input only from the rainfall simulator to having both rainfall simulator input and overland flow input as the existing rill filled over the course of the experiment.

The third experiment, performed on 5 August (Fig. 8c), started with $0.55 \leq \hat{\theta}_{x, 0} \leq 0.78$ and a mean value of 0.67 , placing it in between experiments 1 and 2 in terms of initial soil moisture. However, this experiment was performed with nozzle configuration 3, meaning a rainfall intensity of $31.8 \mathrm{~mm} \mathrm{~h}^{-1}$. As a result, it took nearly $3 \mathrm{~h}$ for the whole plot to reach saturation. Again, probe 12 takes the longest to reach saturation. There is also a sharp change in the slopes of the soil moisture time series for probes 4,5 , and 6 ; for each of these three probes, the change in slope occurs soon after the probes immediately downslope $(8,9$, and 10 , respectively) reach saturation. This feature seems to indicate that gravity drainage downslope does not occur fast enough to keep the saturation front from creeping uphill.

Overall, the time to saturation in each of the three experiments increased as the rainfall intensity and the initial soil moisture decreased, as expected. To investigate the relationship between the location of the soil moisture probes and the spatial variability of the measurements, the soil moisture results have been categorized by location. Probes 2, 3, 5, 6, 9, 10,13 , and 14 are considered interior probes, and the remaining are considered border probes. Figure 9 shows the comparison of the averages of the interior and border soil moisture probes compared to the overall average. In each case, the border soil moisture probes overall have lower readings than the interior probes. The difference is particularly pronounced in experiment 2 , when the difference between the interior and border probes in the middle of the experiment exceeds the difference in the initial values. This is also true, to a lesser degree, in experiment 3. A possible explanation for the discrepancy is that the rainfall intensity distribution as shown in Fig. 6 generally appears to favor the interior of the plot over the edges.

\subsection{Runoff}

The tips of the tipping bucket flow gauge were converted to time series of runoff rate and cumulative runoff through Eq. (1). Specifically, with $t_{i}$ being the time in minutes of the $i$ th bucket tip and $V_{i}$ the volume of that tip in liters, the runoff rate $q_{i}$ in $\mathrm{mm} \mathrm{h}^{-1}$ is

$q_{i}=\frac{V_{i}}{t_{i}-t_{i-1}} \cdot \alpha$,

where

$$
\begin{aligned}
\alpha & =60 \mathrm{minh}^{-1} \cdot 0.001 \mathrm{~m}^{3} \mathrm{~L}^{-1} \cdot 1000 \mathrm{~mm} \mathrm{~m}^{-1} / 15.12 \mathrm{~m}^{2} \\
& =3.968
\end{aligned}
$$

is the constant that converts $\mathrm{L} \mathrm{min}^{-1}$ to $\mathrm{mm} \mathrm{h}^{-1}$. The infiltration rate that results from this runoff is

$i_{i}=p-q_{i}$ 

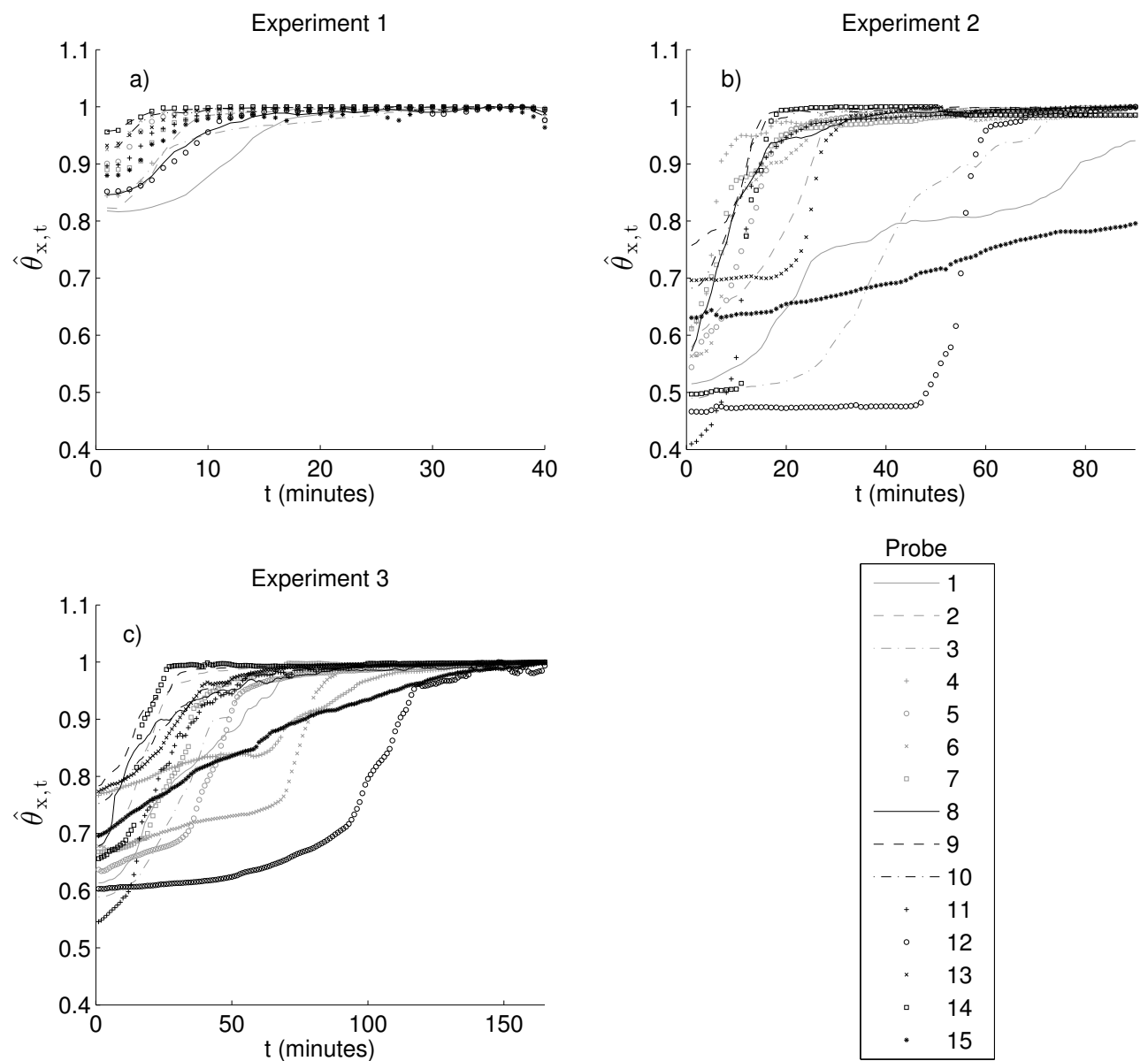

Figure 8. Soil moisture as $\hat{\theta}_{x, t}$ for each TDR probe. (a) Experiment 1. The soil started near saturation due to previous test runs. (b) Experiment 2. (c) Experiment 3.
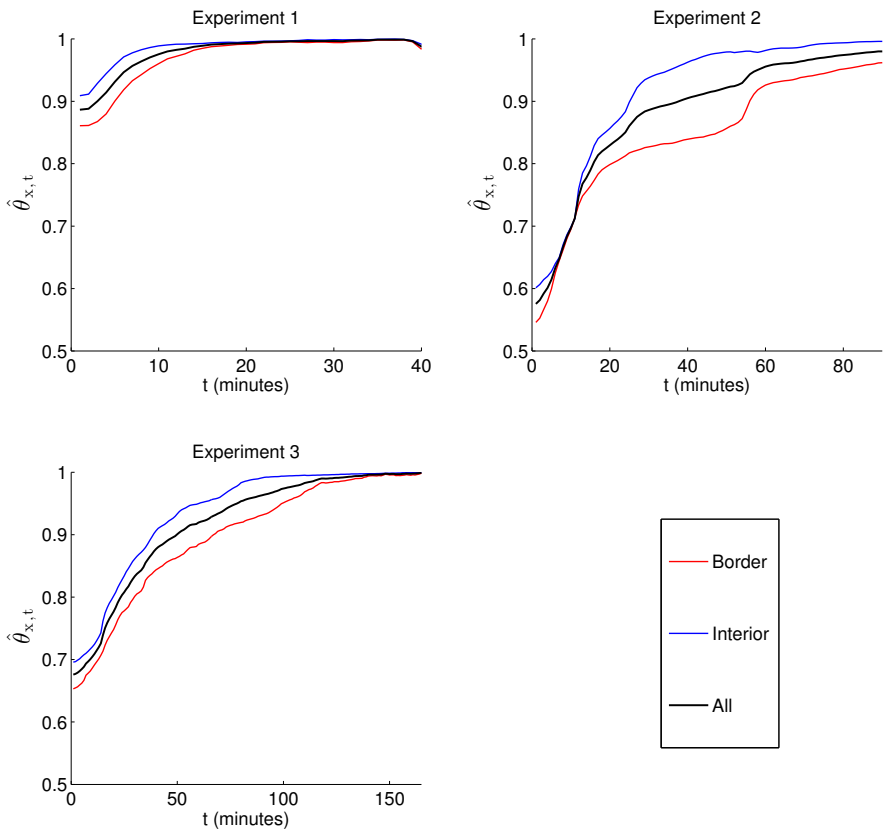

Figure 9. Soil moisture averaged for all probes, border probes, and interior probes for the three experiments. 

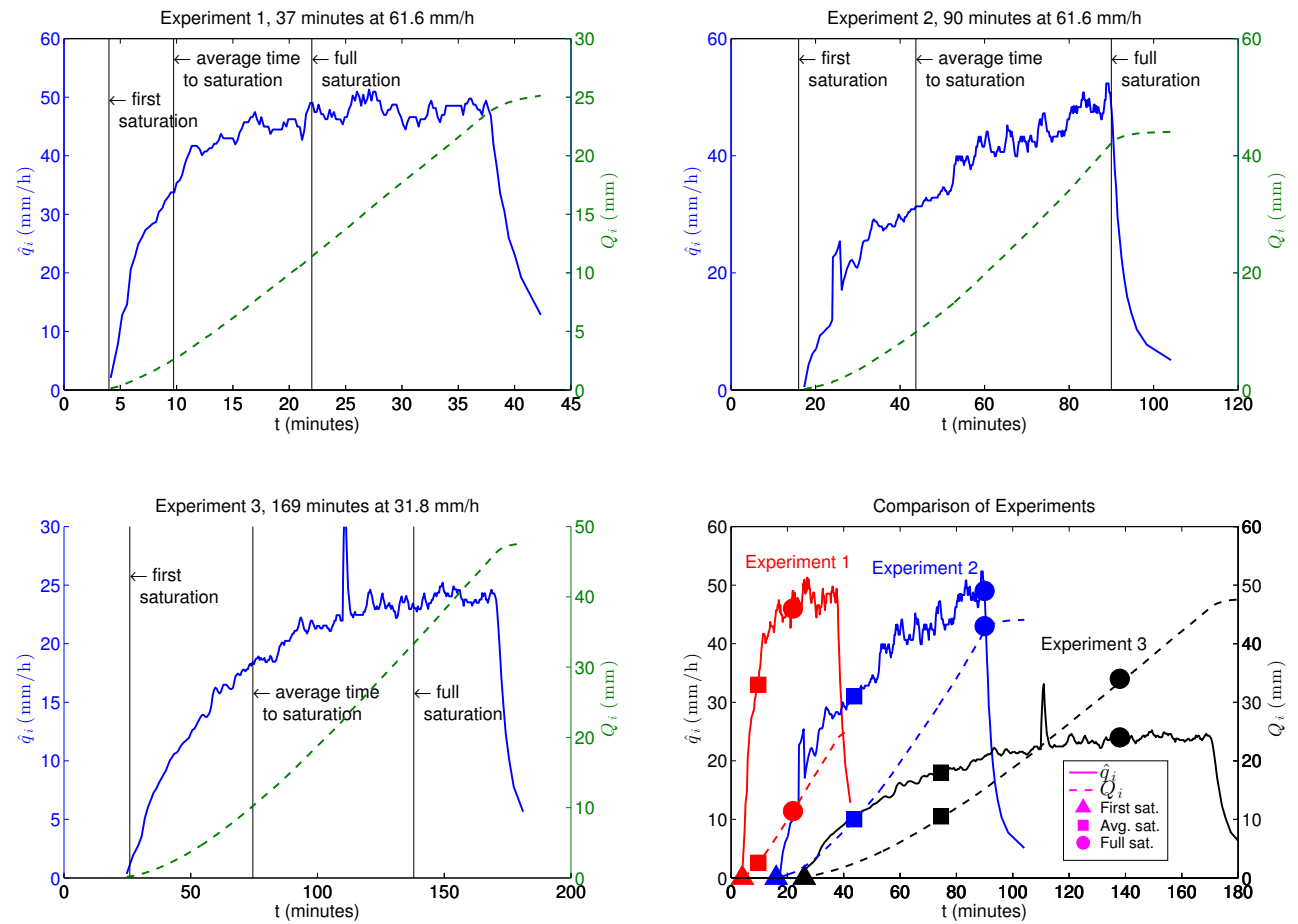

Figure 10. Runoff rate and cumulative runoff for the three experiments. The vertical lines represent times when the soil moisture probes reached maximum values.

The cumulative runoff $Q_{i}$ is

$Q_{i}=\sum_{j=0}^{i} V_{j} \cdot \beta$,

where

$\beta=0.001 \mathrm{~m}^{3} \mathrm{~L}^{-1} \cdot 1000 \mathrm{~mm} \mathrm{~m}^{-1} / 15.12 \mathrm{~m}^{2}=0.06614$

converts $\mathrm{L}$ to $\mathrm{mm}$. Since the tipping bucket flow gauge causes $q_{i}$ to oscillate around what should be a smooth time series, a four-point moving average was calculated as

$\hat{q}_{i}=\frac{1}{4} \sum_{j=i-3}^{i} q_{j}$.

Figure 10 shows both $\hat{q}_{i}$ and $Q_{i}$, in addition to the times at which the soil moisture probes reached full saturation. These figures provide a visual check of whether or not the rainfall simulator provides reasonable results. In each of the three experiments, runoff begins approximately when the first probe reaches saturation. The first probe to reach saturation in all three experiments was probe 14 , which is next to the outlet of the plot. With $t_{x, \mathrm{~s}}$ as the time when probe $x$ reaches saturation, the average time to saturation for each experiment, $\overline{t_{\mathrm{s}}}$, is defined as $\frac{1}{n} \sum_{x=1}^{n} t_{x, \mathrm{~s}}$ with $n=15 . \overline{t_{\mathrm{s}}}$ occurs while the runoff rate is increasing, and the runoff rate changes little after the final probe reaches saturation. The exception is experiment 2, which did not continue beyond time when the final probe reached saturation.
It is also useful to compare the runoff rates between experiments. For both experiments 1 and 2, the average of the runoff rates near the end of the experiment is approximately $47.6 \mathrm{~mm} \mathrm{~h}^{-1}$. When compared to the applied rainfall rate of $61.6 \mathrm{~mm} \mathrm{~h}^{-1}$, the final runoff coefficient $\left(C_{\mathrm{f}}=q_{\mathrm{f}} / p\right)$ once the plot is fully saturated is 0.77 . For experiment 3 , the average runoff rate near the end of the experiment is $24.2 \mathrm{~mm} \mathrm{~h}^{-1}$, or $C_{\mathrm{f}}=0.76$. The similar runoff coefficients emphasize the proportionality between rainfall and runoff rates.

The overall runoff coefficient is

$C=Q_{\mathrm{f}} / P$,

where $Q_{\mathrm{f}}$ is the cumulative runoff for the entire experiment and $P$ is the total precipitation applied during duration $T$. While the $C_{\mathrm{f}}$ values are equivalent across the experiments, the $C$ values differ, with values of $0.61,0.46$, and 0.51 . This is expected due to the varying antecedent soil moisture states as higher $\theta_{0}$ values correspond to higher $C$ values. Therefore, in this brief analysis of the measured data of soil moisture and runoff, the experiments show that the rainfall simulator produces physically reasonable results.

\subsection{Parameter estimation}

Using the estimation method shown in Sect. 5, the $K_{\mathrm{s} \text {, surf }}$ values for the experiments 1,2 , and 3 are $16.5,8.56$, and

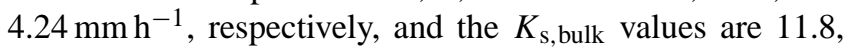



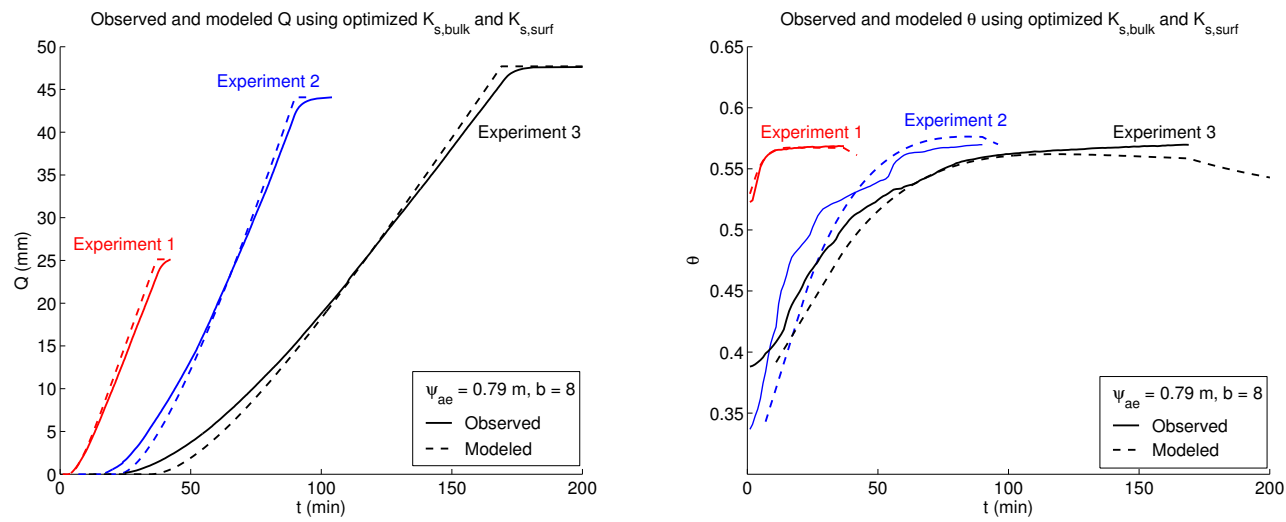

Figure 11. Observed and modeled $Q$ and $\theta$ based on optimized hydraulic conductivities for the three experiments with $\psi_{\mathrm{ae}}=0.79 \mathrm{~m}$ and $b=8$. Optimized hydraulic conductivity values are as follows: experiment $1: K_{\mathrm{s}, \text { surf }}=16.5 \mathrm{~mm} \mathrm{~h}^{-1}, K_{\mathrm{s}, \text { bulk }}=11.8 \mathrm{~mm} \mathrm{~h}^{-1}$; experiment 2 : $K_{\mathrm{S}, \text { surf }}=8.56 \mathrm{~mm} \mathrm{~h}^{-1}, K_{\mathrm{s}, \text { bulk }}=7.48 \mathrm{~mm} \mathrm{~h}^{-1}$; and experiment $3: K_{\mathrm{s}, \text { surf }}=4.24 \mathrm{~mm} \mathrm{~h}^{-1}, K_{\mathrm{s}, \text { bulk }}=8.20 \mathrm{~mm} \mathrm{~h}^{-1}$.

7.48 , and $8.20 \mathrm{~mm} \mathrm{~h}^{-1}$. Verbist et al. (2009) found a $K_{\mathrm{S}}$ range of approximately 17 to $55 \mathrm{~mm} \mathrm{~h}^{-1}$ for a coarse loamy soil for four replicates at $120 \mathrm{~mm} \mathrm{~h}^{-1}$ precipitation intensity. Since our experiments were performed at two different precipitation intensities, we consider the overall range of 4.24 to $16.5 \mathrm{~mm} \mathrm{~h}^{-1}$ to be acceptable.

The comparison of the observed and modeled time series based on these hydraulic conductivity values is shown in Fig. 11. Additionally, the observed final infiltration rate for each experiment is defined as

$i_{\mathrm{f}}=p-\frac{\sum_{t=t_{\mathrm{c}}}^{T} q_{t} \Delta t}{T-t_{\mathrm{c}}}$,

where $t_{\mathrm{c}}$ is the time at which the infiltration and runoff appear to become constant. The comparison of $K_{\mathrm{s}, \text { surf }}, K_{\mathrm{s} \text {, bulk }}$, and $i_{\mathrm{f}}$ is shown in Fig. 12. The parameter which shows the largest range over the three experiments is $K_{\mathrm{s} \text {,surf. One possible rea- }}$ son for the reduction in $K_{\mathrm{s} \text {, surf }}$, particularly between the first two experiments, is surface sealing that can occur after water is applied to the surface. Another reason for the difference between $K_{\mathrm{s} \text {, surf }}$ in experiments 1 and 2 and that of experiment 3 is the smaller rainfall intensity in the third experiment. The most stable values are for $K_{\mathrm{s} \text {, bulk }}$. This is likely due to the behavior of the bulk soil being less affected by the conditions that vary between experiments. The literature value of saturated hydraulic conductivity for a silt loam with a mean clay fraction of 0.14 is approximately $25 \mathrm{~mm} \mathrm{~h}^{-1}$ (Clapp and Hornberger, 1978). The optimized values here are smaller, despite having a clay fraction of 0.05 . One possible reason for the disparity is the high silt fraction in this soil $(0.76)$. The most apparent reason, however, is that field values of saturated hydraulic conductivity are highly dependent on rainfall intensity (e.g., Bowyer-Bower, 1993; Stone et al., 2008; Langhans et al., 2010). Larger experimental rainfall intensi-

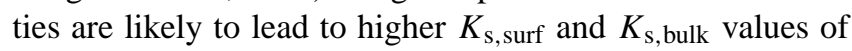
this soil.

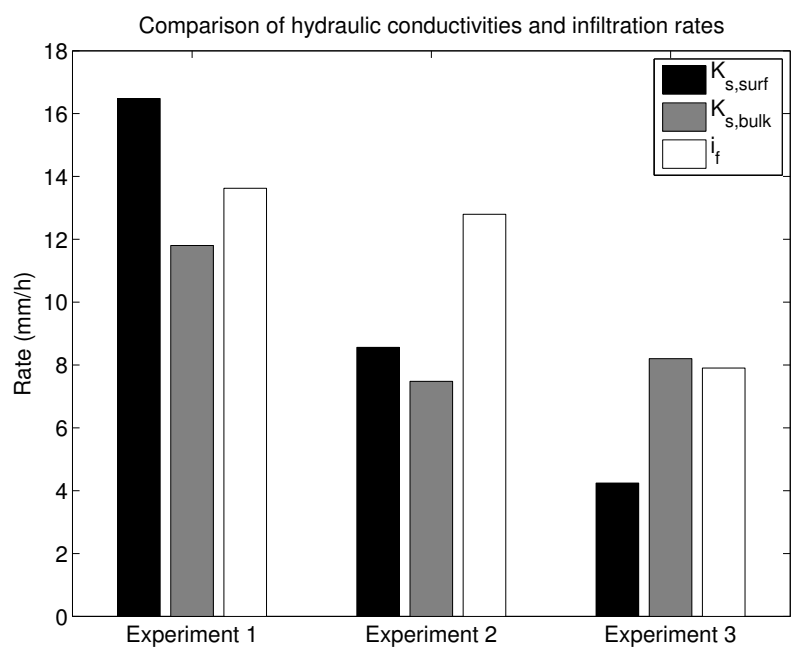

Figure 12. Comparison of infiltration and conductivity rates for the three experiments.

Since the soil properties do not change between experiments, ideally the range of $K_{\mathrm{s} \text {, surf }}$ and $K_{\mathrm{s} \text {,bulk values should }}$ be smaller than what is shown in Fig. 12. The remaining model parameters that have not been determined by field data are $b$ and $\psi_{\mathrm{ae}}$, so they can be included in the optimization. Values of $b$ from 5 to 9 with a step of $\Delta b=1$ and values of $\psi_{\mathrm{ae}}$ from 0.3 to $0.8 \mathrm{~m}$ with $\Delta \psi_{\mathrm{ae}}=0.083 \mathrm{~m}$ were incorporated into the parameter space so each model realization used a unique combination of the four parameters. Again, the parameter assignment that minimized $e^{*}$ was selected as the optimal set for each equation. These results are shown in the second block of Table 4 .

$b$ and $\psi_{\text {ae }}$ are constant for one plot, so the final step was to average the values of $b$ and $\psi_{\text {ae }}$ for the three experiments to get the optimal values $\hat{b}=7$ and $\hat{\psi}_{\mathrm{ae}}=0.44 \mathrm{~m}$. The model was run using $\hat{b}$ and $\hat{\psi}_{\mathrm{ae}}$ along with the combinations of 
Table 4. Parameters for the model optimization (a) using assumed values of $b$ and $\psi_{\mathrm{ae}}$, (b) including all four parameters in the optimization, and (c) using $\hat{\psi}_{\mathrm{ae}}$ and $\hat{b}$.

\begin{tabular}{ccccccc}
\hline Experiment & $\begin{array}{c}K_{\mathrm{s}, \text { bulk }} \\
\mathrm{mm} \mathrm{h}^{-1}\end{array}$ & $\begin{array}{c}K_{\mathrm{s}, \text { surf }} \\
\mathrm{mm} \mathrm{h}^{-1}\end{array}$ & $\begin{array}{c}b \\
{[-]}\end{array}$ & $\begin{array}{c}\psi_{\mathrm{ae}} \\
\mathrm{m}\end{array}$ & $\begin{array}{c}e_{\theta} \\
{[-]}\end{array}$ & $\begin{array}{c}e_{Q_{\mathrm{f}}} \\
\mathrm{mm}\end{array}$ \\
\hline (a) Optimization with assumed $\psi_{\mathrm{ae}}$ and $b$ & & & \\
\hline 1 & 11.8 & 16.5 & & & $2.84 \times 10^{-3}$ & $6.94 \times 10^{-3}$ \\
2 & 7.48 & 8.56 & 8 & 0.79 & $2.45 \times 10^{-2}$ & $6.61 \times 10^{-5}$ \\
3 & 8.20 & 4.24 & & & $8.21 \times 10^{-3}$ & $2.10 \times 10^{-2}$
\end{tabular}

(b) Optimization using all parameters

\begin{tabular}{lllllll}
\hline 1 & 11.2 & 18.0 & 5 & 0.63 & $2.69 \times 10^{-3}$ & $4.63 \times 10^{-4}$ \\
2 & 13.7 & 14.8 & 9 & 0.38 & $2.10 \times 10^{-2}$ & $8.60 \times 10^{-4}$ \\
3 & 6.52 & 8.68 & 7 & 0.30 & $5.50 \times 10^{-3}$ & $2.12 \times 10^{-3}$ \\
\hline
\end{tabular}

(c) Optimization using $\hat{\psi}_{\mathrm{ae}}$ and $\hat{b}$

\begin{tabular}{lllllll}
\hline 1 & 11.8 & 18.6 & & & $2.82 \times 10^{-3}$ & $2.05 \times 10^{-3}$ \\
2 & 12.5 & 13.6 & 7 & 0.44 & $2.10 \times 10^{-3}$ & $6.94 \times 10^{-3}$ \\
3 & 6.04 & 6.76 & & & $6.50 \times 10^{-3}$ & $5.56 \times 10^{-2}$ \\
\hline
\end{tabular}
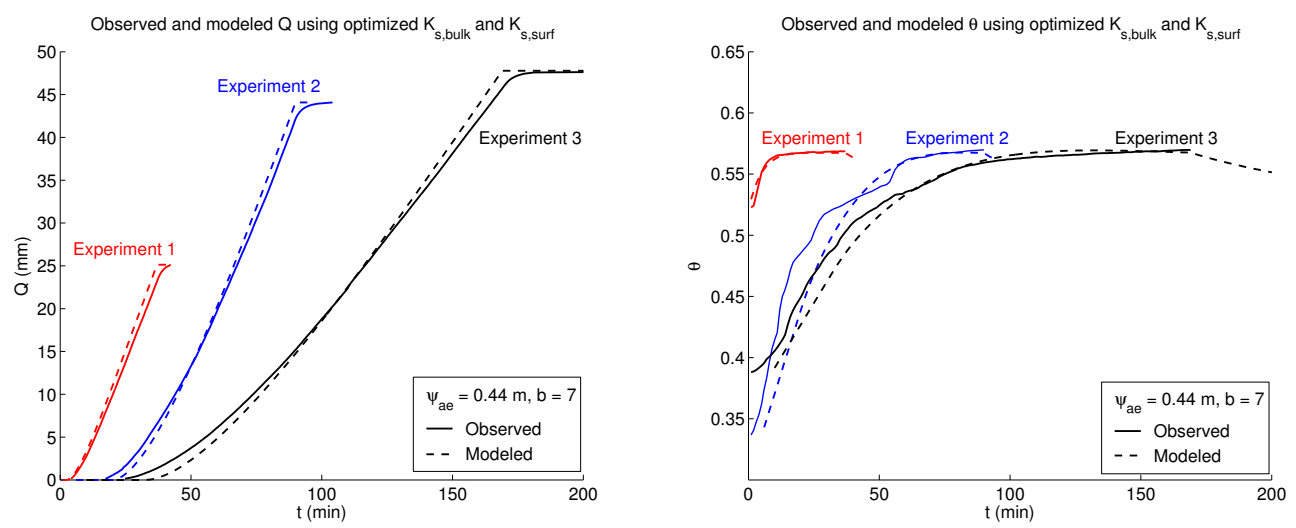

Figure 13. Observed and modeled $Q$ and $\theta$ using $\hat{b}=7$ and $\hat{\psi}_{\mathrm{ae}}=0.44 \mathrm{~m}$. Optimized hydraulic conductivity values are as follows: experiment $1: K_{\mathrm{s}, \text { surf }}=18.6 \mathrm{~mm} \mathrm{~h}^{-1}, K_{\mathrm{s}, \text { bulk }}=11.8 \mathrm{~mm} \mathrm{~h}^{-1}$; experiment $2: K_{\mathrm{s} \text {, surf }}=13.6 \mathrm{~mm} \mathrm{~h}^{-1}, K_{\mathrm{s}, \text { bulk }}=12.5 \mathrm{~mm} \mathrm{~h}^{-1}$; and experiment 3: $K_{\mathrm{s} \text {, surf }}=6.76 \mathrm{~mm} \mathrm{~h}^{-1}, K_{\mathrm{s}, \text { bulk }}=6.04 \mathrm{~mm} \mathrm{~h}^{-1}$.

$K_{\mathrm{s}, \text { surf }}$ and $K_{\mathrm{s} \text {,bulk }}$ used in the first optimization. The values that minimize $e^{*}$ are $K_{\mathrm{s}, \text { surf }}=11.8,12.5$, and $6.04 \mathrm{~mm} \mathrm{~h}^{-1}$, along with $K_{\mathrm{s} \text {,bulk }}=18.6,13.6$, and $6.76 \mathrm{~mm} \mathrm{~h}^{-1}$. The modeled $Q$ and $\theta$ are shown in Fig. 13, Fig. 14 shows the rate comparison, and the overall results are in Table 4 . The $K_{\mathrm{s} \text {,bulk }}$ values for the higher intensity experiments are close to the $18 \mathrm{~mm} \mathrm{~h}^{-1}$ that is expected for this soil, which indicates that, despite the heterogeneity of rainfall intensity throughout the plot, this rainfall simulator can be used to generate reasonable estimates of the primary soil properties that govern infiltration and runoff.

While little difference can be seen between Figs. 11 and 13, a comparison of Figs. 12 and 14 emphasizes the changes in $K_{\mathrm{s} \text {, surf }}$ and $K_{\mathrm{s} \text {, bulk following the optimization pro- }}$ cess. The ranges of the rates for experiments 2 and 3 are smaller than the ranges using the previously assumed values for $b$ and $\psi_{\mathrm{ae}}$. Additionally, $K_{\mathrm{s} \text {, bulk }}$ is closer to the final infiltration rate, particularly for experiment 2 , and the $K_{\mathrm{s} \text {, bulk val- }}$ ues for experiments 1 and 2 are more comparable, which is an improvement since these two experiments have the same water application rate. The reduction in $K_{\mathrm{s} \text {,surf }}$ from experiment 1 to experiment 2 is still present, which is still likely a result of surface sealing in between experiments. Since the values of $K_{\mathrm{s} \text {,surf }}$ and $K_{\mathrm{s} \text {, bulk }}$ are more consistent within experiments and across experiments, it appears that this optimization method has improved the estimates for the saturated hydraulic conductivities of the soil in this plot. 


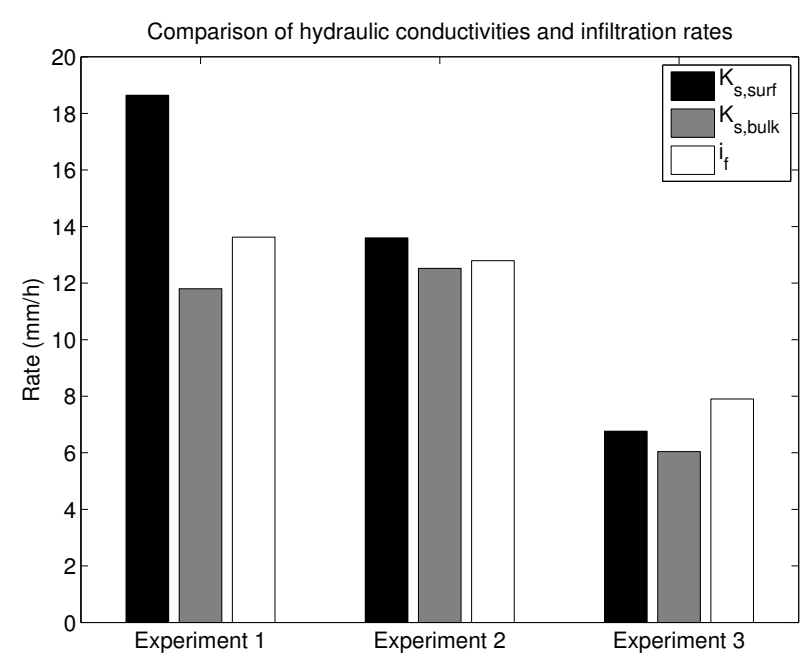

Figure 14. Rates for the optimization using $\hat{b}$ and $\hat{\psi}_{\mathrm{ae}}$.

\section{Conclusions}

This paper presented the design, construction, and testing of a low-cost rainfall simulator system. This system has several significant advantages. Primarily, it is constructed from readily available and inexpensive materials. Additionally, the $4 \mathrm{~m} \times 4 \mathrm{~m}$ module can be replicated to expand the areal coverage of the simulator. It is fairly easy to change the configuration of the system to produce different intensities, and the low operating pressure means that the power requirements of the system are low as well.

There are some limitations of the system. The rainfall intensity pattern is not as uniform as typically desired for rainfall simulators. Additionally, since some water falls on the surface outside the effective irrigated area, the simulator is not as water efficient as it could be. Due to the low operating pressure, the system needs to be close to level to provide even distribution of water, so it cannot be used on steep slopes without changing the frame to include adjustable-height legs. Finally, since the water is sprayed upwards, the system does not work properly in windy conditions without wind shields that are at least $3 \mathrm{~m}$ tall in place around the plot frame.

After measuring soil moisture and runoff during three experimental runs of the system, analysis using the Philip infiltration model showed that this rainfall simulator can produce data that allow for the estimation of reasonable values for the saturated hydraulic conductivity of the soil. Specifically, we showed that performing a three-step parameter search optimization that first estimates $K_{\mathrm{S}}$ with assumed values of $b$ and $\psi_{\mathrm{ae}}$, then estimates $b$ and $\psi_{\mathrm{ae}}$ using the $K_{\mathrm{s}}$ initial estimates, and then uses $\hat{b}$ and $\hat{\psi}_{\text {ae }}$ to get new values for the $K_{\mathrm{s}}$ estimates allows for the estimation of a total of four soil hydraulic parameters. The implication of this result is the ability to use this rainfall simulator system to estimate parameters needed for hydrologic modeling with less reliance on prior knowledge.
Continued work with this system will be to use the rainfall simulator on plots with different vegetation fractions, types, and patterns. The purpose of gathering the data in these different conditions will be to calibrate model parameters for a coupled hydrologic-vegetation dynamics model. This model will be used to investigate how changes in vegetation growth during the transition from the rainy season to the dry season in Sardinia will affect overall surface runoff volumes.

Acknowledgements. This work was supported by NSF grant no. EAR-08-38301, NSF IGERT grant no. DGE-1068871, and by the Regione Sardegna LR 7/2007 through grant no. CRP2_708.

Edited by: T. P. A. Ferre

\section{References}

Alberts, E., Nearing, M., Weltz, M., Risse, L., Pierson, F., Zhang, X., Laflen, J., and Simanton, J.: Soil component, Chap. 7, in: USDA Water Erosion Prediction Project (WEPP): Hillslope Profile and Watershed Model Documentation, edited by: Flanagan, D. C. and Nearing, M. A., NESRL Report No. 10, USDA-ARS National Soil Erosion Research Laboratory, West Lafayette, IN, 1995.

Battany, M. C. and Grismer, M. E.: Development of a portable field rainfall simulator for use in hillside vineyard runoff and erosion studies, Hydrol. Process., 14, 1119-1129, 2000.

Bhardwaj, A. and Singh, R.: Development of a portable rainfall simulator infiltrometer for infiltration, runoff and erosion studies, Agr. Water Manage., 22, 235-248, 1992.

Bowyer-Bower, T. A. S.: Effects of rainfall intensity and antecedent moisture on the steady-state infiltration rate in a semi-arid region, Soil Use Manage., 9, 69-76, 1993.

Campbell, G. S.: A simple method for determining unsaturated conductivity from moisture retention data, Soil Sci., 117, 311-314, 1974.

Cerdà, A., Ibáñez, S., and Calvo, A.: Design and operation of a small and portable rainfall simulator for rugged terrain, Soil Technol., 11, 163-170, 1997.

Chow, T. L.: A low-cost tipping bucket flow meter for overland flow and subsurface stormflow studies, Can. J. Soil Sci., 56, 197-202, 1976.

Christiansen, J. F.: Irrigation by Sprinkling, California Agricultural Experiment Station Bulletin 670, University of California, Berkeley, CA, 1942.

Clapp, R. B. and Hornberger, G. M.: Empirical equations for some soil hydraulic properties, Water Resour. Res., 14, 601-604, 1978.

Corona, R.: The role of vegetation on hydrological processes of Mediterranean ecosystems under water-limited conditions, Ph.D. thesis, Università di Cagliari, Cagliari, Italy, 2013.

Dingman, S. L.: Physical Hydrology, 2nd Edn., Prentice Hall, Upper Saddle River, NJ, 2004.

Dunne, T., Zhang, W., and Aubry, B. F.: Effects of rainfall, vegetation, and microtopography on infiltration and runoff, Water Resour. Res., 27, 2271-2285, 1991. 
Eagleson, P. S.: Climate, soil, and vegetation: 3. A simplified model of soil moisture movement in the liquid phase, Water Resour. Res., 14, 722-730, 1978.

Esteves, M., Planchon, O., Lapetite, J., Silvera, N., and Cadet, P.: The "EMIRE" large rainfall simulator: design and field testing, Earth Surf. Proc. Land., 25, 681-690, 2000.

Fernandez-Galvez, J., Barahona, E., and Mingorance, M. D.: Measurement of infiltration in small field plots by a portable rainfall simulator: application to trace-element mobility, Water Air Soil Poll., 191, 257-264, 2008.

Fister, W., Iserloh, T., Ries, J. B., and Schmidt, R.-G.: A portable wind and rainfall simulator for in situ soil erosion measurements, Catena, 91, 72-84, 2012.

Foster, I. D. L., Fullen, M. A., Brandsma, R. T., and Chapman, A. S.: Drip-screen rainfall simulators for hydro- and pedogeomorphological research: the Coventry experience, Earth Surf. Proc. Land., 25, 691-707, 2000.

García-Ruiz, J., Arnáez, J., Beguería, S., Seeger, M., Martí-Bono, C., Regüés, D., Lana-Renault, N., and White, S.: Runoff generation in an intensively disturbed, abandoned farmland catchment, Central Spanish Pyrenees, Catena, 59, 79-92, 2005.

Genxu, W., Guangsheng, L., and Chunjie, L.: Effects of changes in alpine grassland vegetation cover on hillslope hydrological processes in a permafrost watershed, J. Hydrol., 444-445, 22-33, 2012.

Grierson, I. T. and Oades, J. M.: A rainfall simulator for field studies of run-off and soil erosion, J. Agr. Eng. Res., 22, 37-44, 1977.

Kool, J. B., Parker, J. C., and van Genuchten, M. T.: Determining soil hydraulic properties from one-step outflow experiments by parameter estimation: I. Theory and numerical studies, Soil Sci. Soc. Am. J., 49, 1348-1354, 1985.

Lana-Renault, N., Latron, J., Karssenberg, D., Serrano-Muela, P., Regüés, D., and Bierkens, M. F. P.: Differences in stream flow in relation to changes in land cover: a comparative study in two subMediterranean mountain catchments, J. Hydrol., 411, 366-378, 2011.

Langhans, C., Govers, G., Diels, J., Clymans, W., and Van den Putte, A.: Dependence of effective hydraulic conductivity on rainfall intensity: loamy agricultural soils, Hydrol. Process., 24, 2257-2268, 2010.

Lassabatere, L., Angulo-Jaramillo, R., Soria-Ugalde, J. M., Cuenca, R., Braud, I., and Haverkamp, R.: Beerkan estimation of soil transfer parameters through infiltration experiments - BEST, Soil Sci. Soc. Am. J., 70, 521-532, 2006.

Maetens, W., Vanmaercke, M., Poesen, J., Jankauskas, B., Jankauskiene, G., and Ionita, I.: Effects of land use on annual runoff and soil loss in Europe and the Mediterranean: A metaanalysis of plot data, Prog. Phys. Geog., 36, 599-653, 2012.

Montaldo, N., Albertson, J. D., and Mancini, M.: Vegetation dynamics and soil water balance in a water-limited Mediterranean ecosystem on Sardinia, Italy, Hydrol. Earth Syst. Sci., 12, 12571271, doi:10.5194/hess-12-1257-2008, 2008.

Moore, I. D., Hirschi, M. C., and Barfield, B. J.: Kentucky rainfall simulator, T. ASAE, 26, 1085-1089, 1983.

Morán-Tejeda, E., Ceballos-Barbancho, A., and Llorente-Pinto, J. M.: Hydrological response of Mediterranean headwaters to climate oscillations and land-cover changes: the mountains of Duero River basin (Central Spain), Global Planet. Change, 72, 39-49, 2010.
Neff, E.: Why rainfall simulation?, Agricultural Reviews and Manuals ARM-W-10, in: Proceedings of the Rainfall Simulator Workshop, Tucson, Arizona, 3-7, 1979.

Olyphant, G. A.: Temporal and spatial (down profile) variability of unsaturated soil hydraulic properties determined from a combination of repeated field experiments and inverse modeling, J. Hydrol., 281, 23-35, 2003.

Philip, J. R.: The theory of infiltration: 4. Sorptivity and algebraic infiltration equations, Soil Sci., 84, 257-264, 1957.

Philip, J. R.: General method of exact solution of the concentrationdependent diffusion equation, Aust. J. Phys., 13, 1-12, 1960.

Ram, S., Prasad, K. S. H., Gairola, A., Jose, M. K., and Trivedi, M. K.: Estimation of border-strip soil hydraulic parameters, J. Irrig. Drain. E.-ASCE, 138, 493-502, 2012.

Ramos, T. B., Goncalves, M. C., Martins, J. C., van Genuchten, M. T., and Pires, F. P.: Estimation of soil hydraulic properties from numerical inversion of tension disk infiltrometer data, Vadose Zone J., 5, 684-696, 2006.

Rienzner, M. and Gandolfi, C.: Investigation of spatial and temporal variability of saturated soil hydraulic conductivity at the fieldscale, Soil Till. Res., 135, 28-40, 2014.

Romero, M. N., Martínez, T. L., Regüés, D., Lana-Renault, N., and Cerdà, A.: Hydrological response and sediment production under different land cover in abandoned farmland fields in a mediterranean mountain environment, B. Asoc. Geogr. Esp., 55, 303323, 2011.

Russo, D., Bresler, E., Shani, U., and Parker, J. C.: Analyses of infiltration events in relation to determining soil hydraulic properties by inverse problem methodology, Water Resour. Res., 27, 13611373, 1991.

Sauvageout, H. and Lacaux, J.-P.: The shape of averaged drop size distributions, J. Atmos. Sci., 52, 1070-1083, 1995.

Segal, E., Bradford, S. A., Shouse, P., Lazarovitch, N., and Corwin, D.: Integration of hard and soft data to characterize field-scale hydraulic properties for flow and transport studies, Vadose Zone J., 7, 878-889, 2008.

Simunek, J. and van Genuchten, M. T.: Estimating unsaturated soil hydraulic properties from tension disc infiltrometer data by numerical inversion, Water Resour. Res., 32, 2683-2696, 1996.

Sivapalan, M., Beven, K., and Wood, E. F.: On hydrologic similarity: 2. A scaled model of storm runoff production, Water Resour. Res., 23, 2266-2278, 1987.

Stone, J. J., Paige, G. B., and Hawkins, R. H.: Rainfall intensitydependent infiltration rates on rangeland rainfall simulator plots, T. ASABE, 51, 45-53, 2008.

Swanson, N. P.: Rotating-boom rainfall simulator, T. ASAE, 8, 7172, 1965.

Verbist, K., Cornelis, W. M., Gabriels, D., Alaerts, K., and Soto, G.: Using an inverse modelling approach to evaluate the water retention in a simple water harvesting technique, Hydrol. Earth Syst. Sci., 13, 1979-1992, doi:10.5194/hess-13-1979-2009, 2009.

Xu, X., Lewis, C., Liu, W., Albertson, J. D., and Kiely, G.: Analysis of single-ring infiltrometer data for soil hydraulic properties estimation: Comparison of BEST and Wu methods, Agr. Water Manage., 107, 34-41, 2012. 